\title{
A study on the relationships of place attachment and individual attributes of residents in different vulnerable districts in Taipei, Taiwan
}

\author{
Yung-Jaan Lee ${ }^{1}$ (1) $\cdot$ Shih-Ying Lin ${ }^{1}$ \\ Received: 10 October 2020 / Accepted: 9 March 2021 / Published online: 13 March 2021 \\ (C) Springer-Verlag GmbH Germany, part of Springer Nature 2021
}

\begin{abstract}
Under the impact of climate change, Taiwan, an island state, has faced the challenges of extreme weather events in recent years. Based on previous studies on climate change and vulnerability in Taipei, Taiwan, this study explores the correlations between place attachment and individual attributes of residents in different vulnerable areas in Taipei. First, this study investigates the integrated vulnerability (IV) of 12 districts of Taipei by overlaying natural vulnerability (NV) and social vulnerability (SV). This study selects four districts with high IV and low IV in Taipei, and with a large proportion of flooded areas, as the study sites. Second, a questionnaire survey (600 respondents) is conducted to examine the correlations between place attachment and the individual attributes of the respondents (age, residence duration, disaster experience, and education) in the four districts. Third, factor analyses are carried out to categorize place attachment into four factors: "security," "familiarity," "belongingness," and "rootedness." Finally, whether different factors have different relationships with place attachment are elucidated. The results show no consistent correlations between place attachment and individual attributes in areas with different vulnerabilities. Furthermore, by comparing the correlations before and after factor analyses of place attachment, among the four factors of place attachment (security, familiarity, belongingness, rootedness), there are no factors significantly relating to overall place attachment. This study further examines the mediator effect between risk experience and place attachment. The results show no mediator effects in the relationships of "perception $\rightarrow$ place attachment $\rightarrow$ coping behavior" and "attitude $\rightarrow$ place attachment $\rightarrow$ coping behavior." Follow-up studies can elucidate factor analyses of place attachment and examine the effect of geographical scale (neighborhood, district, and city) on place attachment.
\end{abstract}

Keywords Climate change $\cdot$ Integrated vulnerability $\cdot$ Place attachment $\cdot$ Individual attributes $\cdot$ Coping behavior $\cdot$ Mediator effect · Taipei

\section{Introduction}

In the past 10 years, with the industrialization of the global economy, urbanization, and the widespread application of powerful technological means, human exploitation of resources, ecological destruction, environmental degradation,

Responsible Editor: Philippe Garrigues

Yung-Jaan Lee

yungjaanlee@gmail.com

1 Chung-Hua Institution for Economic Research, Taipei, Taiwan and space occupation have reached an unprecedented scale (Danish et al. 2019; UN 2019). Ecological transformation, tolerance, and opposition to inequality are interdependent and must be resolved at the same time (Convergences 2019). Due to the influence of industrialization and urbanization, climate change has undergone significant changes in population growth and economic development in the past two decades. Therefore, climate change mitigation and adjustment have become politically important (Kelman et al. 2015; Okitasari et al. 2019). The United Nations also proposed "the city of the 21 st century is a city that reduces the disaster risk and vulnerability of all people, including the poor, and must strengthen the ability to resist any undesirable forces of nature" (UN Habitat 2013). 
The phenomenon of climate change points out human activities may cause significant changes in the earth's average surface warming in the next 50 years. Therefore, politically, the global economy, society, and morality must respond to climate change with policy leadership and environmental education measures (Kellogg and Schware 2019). According to the "Global Climate Risk Index 2020" (Eckstein et al. 2020), in 2018, Taiwan ranked 75th in caused disasters or risks due to climate change, compared to 90th in 2017 (Eckstein et al. 2019). The variation of the risk index indicates the unpredictability of disasters and deepens the importance of responding to climate change risks (Jiang et al. 2017).

By the end of the 20th century, the greenhouse effect in cities was significantly more pronounced than in rural areas, and the climate had also changed considerably during the same period. Water issues related to cities attracted the attention of the global scientific community. For example, excessive use of "gray construction" such as concrete and asphalt in urban development has resulted in impervious surfaces that cannot absorb water (Nguyen et al. 2019). Urban floods caused by river flooding, flash floods, and drainage problems are natural disasters having the greatest impact on the number of people affected and economic losses (Domeneghetti et al. 2015; Gu et al. 2018; Jiang et al. 2017; Tate et al. 2021). Therefore, in the case of multiple exposures, people who live in environmentally sensitive areas should have different risk perceptions when facing the global warming challenges in Taipei, which has high SI. Among them, floods accounted for one-third of the world's natural disasters and one-third of economic loss. They are considered the most influential disasters (White 2000) and the most direct impact events (Domeneghetti et al. 2015). Previous studies also suggested floods were highly related to climate change (Cogut et al., 2019; De Dominicis et al. 2015).

AlQahtany and Abubakar (2020) pointed out among numerous types of natural disasters, floods cause the highest casualties. People's perceptions of flood risk may be affected by emotions, experiences, or the destructive effects of earthquakes (Ho et al. 2008; Schipper and Pelling 2006). In Taiwan, the risk of a landslide is the highest, followed by floods and earthquakes (Ho et al. 2008). In 2019, in terms of human deaths caused by global disasters, flood disasters ranked first (47\%), followed by storms (24\%). Compared with other natural disasters, global floods have a greater impact on humans (EM-DAT 2020). Flash floods have caused extensive losses and damages to society and are one of the deadliest natural disasters in the world (Khajehei et al. 2020).

On the other hand, the main variables affecting people's behavior in response to climate change include disaster expectations, fear levels, and disaster experience (Takao et al. 2004). Among them, disaster expectations and perception are more closely related to behavior. The relationship between experience and behavior is relatively weak (van Valkengoed and Steg 2019). Given related research on disaster cognition and awareness can help assess public disaster preparedness, this study focuses on "flood disasters," which differs from previous flood research in water conservancy projects and previous studies on climate change response behavior. Regarding the relationship with disaster experience and perception (van Valkengoed and Steg 2019), this study analyzes the correlation between the individual attributes and place attachment of people in different vulnerable districts. Specifically, this study explores the relationship between four individual attributes (age, residence duration, disaster experience, and education) and the place attachment of respondents in different vulnerable areas. Moreover, whether place attachment exhibits a factor structure, and the relationship between this factor structure and place attachment will be examined.

\section{Literature review}

\section{Climate change and risk perception}

Uncertain factors (e.g., natural disasters, climate change, and energy crisis) play an important role in threatening urban development (Spaans and Waterhout 2017). The IPCC (2014) pointed out climate change was most likely caused by human activities, and its main concerns included global warming, sea-level rise, and extreme weather events. Climate change has become one of the most important and urgent challenges in the world in recent years (IPCC 2018). It is recognized climate change affects the intensity and frequency of natural disasters, coupled with political and socioeconomic inequalities, leading to frequent disaster occurrence (Hudec et al. 2018).

The concept of risk perception originated from the study of cognitive psychology, which contends people use some psychological strategies (heuristics) to understand uncertain events (e.g., disasters) (Motoyoshi 2006). Some studies address the interrelationships among socioeconomic conditions, disasters, and risk perceptions (De Silva and Kawasaki 2018). For example, poor people often live in disaster-prone areas, especially rural areas, because they have no money or resources to live elsewhere (Chan 1995). In the existing disaster prevention and risk response measures, the awareness of a certain aspect of emergency response and disaster preparedness is not necessarily related to the increased awareness and preparedness of other emergencies and/or disasters (e.g., earthquakes, storms, water pollution). Therefore, from the perspective of the capacity to cope with risks, it is encouraged to involve more stakeholders in disaster risk reduction practices (Thorup-Binger and Charania 2019). 


\section{Flood risk}

The reason floods were selected as the research target in climate change-related topics is people are not willing to properly prepare or respond to flood risk information (O'Sullivan et al. 2012). Floods (hydrogeological risks of the environment) represent one of the most catastrophic environmental risks of our time, but the occurrence of floods is underestimated because floods cannot be accurately predicted (Mysiak et al. 2014; Tate et al. 2021). In general, people only remember floods for a short time and tend to overestimate the risk of floods (First Street Foundation 2020; Terpstra et al. 2006).

Due to the geographical characteristics of Taiwan, there are many types of potential natural disasters, among which floods caused by typhoons and heavy rains are the most frequent (Lee et al., 2020). On the other hand, due to rapid urban development in Taiwan, a large number of people flood into urban areas, causing substantial changes in land use patterns. High-density land use makes impermeable areas more extensive, and the water conservation and retention functions are therefore weakened. The decrease in rainfall infiltration has led to increased rainwater runoff, making the existing drainage pipes unable to cope, and the probability of flooding increasing (Qiang et al. 2017). Although floods caused by typhoons and heavy rains are one of the most important natural disasters in Taiwan, the total number of disasters in the past 10 years is the highest among various natural disasters (Chen et al. 2018). Therefore, this study focuses on "flood disasters." Unlike previous flood studies in water conservancy projects, this study elucidates floods and climate risks in different vulnerable areas of Taipei, using place attachment, flood risk perception, and coping behavior as the main research topics.

De Moel et al. (2011) and Koks et al. (2015) pointed out flood exposure refers to valuable people and buildings located in the floodplain, and when extreme rainfall events cause local floods unrelated to the river, pluvial flooding occurs (Jiang et al. 2017). The current flood response focuses mostly on when the high flow of the river flows into the floodplain. It is better to combine the flood maps of the river and the rainy season to draw risk maps of different flood hazards (First Street Foundation 2020). One of the quantitative assessment methods for the impact of floods on society is an integrated analysis, in which a spatial overlay of flood hazards and social vulnerability indicators are superimposed (Tate et al. 2021).

\section{Natural/social vulnerability}

Urban expansion leads to problems such as overconcentration of populations and economies and climate change, which have gradually increased disaster risks. Disaster risks will vary with time, location, exposure, vulnerability, and resilience (Tarhan et al. 2016). Adger (2006) defines vulnerability as the state of susceptibility to harm from exposure to stresses associated with environmental and social change and from the absence of the capacity to adapt. Vulnerability and resilience relate not only to the current state but also to why and how societies take appropriate actions to restore the post-disaster state or to improve disaster resilience in the future (Kelman et al. 2015). Therefore, different vulnerability information in different regions is critical to local resilience and improving sustainability (Jabareen 2015; Khailania and Pererab 2013; Khajehei et al. 2020; Lee and Lin 2019).

Bennett et al. (2014) and Khajehei et al. (2020) propose integrated methods be adopted to assess the vulnerabilities of the study area, including assessment of natural vulnerability (such as climatic conditions, natural disasters, topography, land coverage), socioeconomic factors (such as demographics, poverty, employment, gender), and potential harm of risks (Lee 2014; Sajjad and Jain 2014). Through analyzing natural and social vulnerability, not only the focus of the disaster-affected area needs immediate attention but also efforts can be made to reduce the vulnerable hotspots from the impact of climate change and disasters (Jabareen 2015; Khan 2012; Sajjad and Jain 2014).

Regarding the method of analyzing vulnerability, the geographic information system (GIS) is a powerful tool for analyzing the spatial variability of people who are vulnerable to risks in society, in turn providing vulnerability exposure maps and highlighting locations and residences in highly vulnerable areas (Frigerio et al. 2016; Khajehei et al. 2020).

\section{Sense of place, identity of place, and place attachment}

In recent years, research on related concepts such as place attachment, place identity, identity of place, and place meaning has developed rapidly (Bonaiuto et al. 2016; Lewicka 2011). The relationship between the identity of place and environmental risk perceptions has not yet been clarified. Identity of place affects the importance of perceptions and behavior and needs to be considered for regions with different risk levels. Studies pointed out place attachment, risk perception, and responsive behavior will vary depending on the place people live (Bonaiuto et al. 2016; Casakin et al. 2015; Schilar and Keskitalo 2018).

Place attachment originates from environmental psychology, which covers the individual's connection to home and neighborhoods, and extends to communities and cities, etc., to express the individual's connection to a specific environment. There has been extensive literature review on place attachment and its development in environmental psychology (Lewicka 2011). Another related concept is the identity of place (Casakin et al. 2015; Proshansky et al. 1983; Uzzell 2000), which describes the socialized relationship between the individual and the physical world. Continuing these 
studies and according to the findings of Lewicka (2011), place attachment refers to people's emotional bond to a place; this attachment usually includes part of their individual and collective identity. Place attachment is the emotional factor of the individual's place identity in a particular place and according to "place-specific bias," place attachment may promote or hinder place-related behavior (Bonaiuto et al. 2016; De Dominicis et al. 2015; van Veelen and Haggett 2017). The tripartite framework of Scannell and Gifford (2010) is important for understanding place attachment and its impact on place-related behavior (e.g., behavior supporting the environment under certain circumstances). This framework may help understand "person-environment transactions" in hazardous situations and the coping strategies adopted when attachment and separation issues are threatened (Bonaiuto et al. 2016).

Bonaiuto et al. (2016), De Dominicis et al. (2015), Mishra et al. (2010), and Ruiz and Hernández (2014) elucidate the relationship between place attachment in response to environmental risks and other risk perceptions or intentions. However, due to conflicting research results, the correlation between factors such as vulnerability, place attachment, risk perception, and preventive behavior in different places is still unclear (Bonaiuto et al. 2016; De Dominicis et al. 2015). For example, individuals with strong place attachment are generally less willing to relocate and are more likely to return to dangerous areas after natural disasters (Bonaiuto et al. 2016). De Dominicis et al. (2015) suggested when the perceived risk is high, place attachment may become an obstacle to formulating preventive behavior to respond to flood risks. Gifford (2011), Gifford et al. (2009), and Schultz et al. (2014) pointed out the more the respondents understand risk prevention knowledge, the more they will adopt preventive behavior. Research from China (Zhang et al. 2017), Japan (Nozawa et al. 2008), and the Philippines (Bollettino et al. 2018) also pointed to a positive relationship between risk perception and willingness to mitigate typhoon-related risks. Babcicky and Seebauer (2017) and Jha et al. (2017) suggested the moderating variables affecting risk perception and responsive behavior intention may include place attachment and vulnerability.

Depicted as the "prototypical place" (Lewicka 2010), the home is much more than a residence. People often feel a strong emotional connection with their home (Meagher and Cheadle 2020). In fact, studies evaluating people's place attachment strengths at different geographic scales found people have the strongest place attachments to their homes (relative to the buildings, communities, or cities they live in) (Lewicka 2010). Since place attachment represents a certain relationship between people and place, the attributes of people and place should be related when predicting the possibility of place attachment formation. In fact, decades of research have identified some individual attributes positively related to place attachment, including homeownership (Brown et al. 2003), residence duration (Wing et al. 2017), and the strength of personal social bonds (Lewicka 2010).

\section{Individual attributes}

Residents of a place do not necessarily experience place attachment in a consistent way, and the differences within the place cannot be ignored. One way is to explore the personal characteristics affecting individual place attachment (Lewicka 2011). Restated, it may be valuable to understand how personal characteristics affect place attachment (van Veelen and Haggett 2017). People's risk perceptions, attitudes, and responsive behavior are affected by individual attributes and demographic factors, such as age, education (AlQahtany and Abubakar 2020; Chan et al. 2019), income and location (Alshehri et al. 2016; Chan et al. 2019), disaster types, and previous experiences of floods, landslides, and earthquakes (Ho et al., 2008; Grothmann and Reusswig 2006). Insufficient absorption of risk knowledge by the elderly, traditional myths, or differences in risk and anxiety caused by the disaster experience of the elderly may make age a cause of influence on preventive behavior and attitudes. Chan et al. (2016) found high education, high-risk perception, and responsive behavior are positively correlated, and further pointed out different socioeconomic levels will affect risk perception and responsive behavior.

Jansen (2020) discussed the relationship between place attachment, risk perception, and responsive behavior in a Dutch case study. The results showed strong place attachment is associated with higher age, lower education, and place of birth in the area. Moreover, residence duration is one of the main predictors of place attachment (AlQahtany and Abubakar 2020; Jansen 2020; Razem 2020). Mobility will weaken local bonds, while residence duration will increase local bonds (Lewicka 2011). A positive correlation between place attachment and risk perceptions was found in the context of air pollution in Ontario, Canada. A high sense of locality is related to a high degree of attention to air quality issues. Compared with immigrant women, Canadian-born women have stronger place attachment and risk awareness of air pollution affecting their neighborhood health risks (Bonaiuto et al. 2016). Compared to people born locally, respondents who have moved to Sweden for eight years still believe their place attachment is less bound to municipal borders and not as local as that of others (Schilar and Keskitalo 2018).

van Veelen and Haggett (2017) found long-term residents are more concerned with the long-term future of their communities. Locals may have a functional place attachment to the landscape, rather than an emotional place attachment. According to this view, locals may be more likely to support the development of renewable energy because it is just another way of making a living. Long-term residents believe attachment adopted by (those described as) newcomers is primarily emotional, based on the meaning they give when they first encounter this place, and is often rooted in romantic environmental concepts, namely "wild" and "intact." Place 
attachment is not static. Some people move to a place for certain reasons (e.g., unique landscapes), but many years later, due to their strong social attachment that has developed over time, they still stay in that place (van Veelen and Haggett 2017).

\section{Materials and methods}

\section{Research design}

Taiwan is an East Asian island state located in a subtropical region. The capital city of Taipei is in the northern part of Taiwan and has 12 districts (Fig. 1). Due to the high degree of urbanization, frequent economic and trade activities, high population density, and basin topography, Taipei is a city susceptible to climate change.

Based on the literature review, most studies explore the relationship between risk perceptions and vulnerability, or the relationship between place attachment and individual attributes, and few studies explore whether these relationships have different results in different vulnerable areas. Therefore, under the flood risk of climate change, this study analyzes the correlation between individual attributes of residents in different vulnerable areas and their place attachment.

This study explores the relationship between four individual attributes (age, residence duration, disaster experience, and education) of respondents in different vulnerable areas and place attachment. This study is divided into two parts. The first part is the screening of different vulnerable areas in Taipei. The extremely vulnerable areas in Taipei are used as the research field. The second part is correlation analyses of individual attributes and place attachment in two extremely vulnerable districts. The third part is the analysis of the mediator effects of place attachment.

\section{Selection of different vulnerable areas for Taipei}

This study divides vulnerability into natural vulnerability (NV) and social vulnerability (SV). NV assesses land conditions and disaster potential, whereas SV assesses individual attributes. The following section elucidates the indicators and data sources and then overlays NV and SV using GIS software to generate integrated vulnerability (IV) maps of Taipei.

\section{Natural vulnerability}

This study uses the 2016 disaster potential map of Taiwan's National Disaster Prevention and Rescue Technology Center (NCDR) to calculate the NV. The disaster potential map is a map of areas where disasters may occur, including flooding potential, the impact of debris flow, distribution of active faults, tsunami potential, detritus slide, olistolith, dip slope, and falling rocks (Table 1). This study adopts the eight disaster potential maps as the databank of NV and calculates the distribution area of various $\mathrm{NV}$ and the proportion of the districts to calculate the NV of each district in Taipei.

\section{Social vulnerability}

This study utilized the four dimensions of SV of Taiwan's NCDR (exposure, disaster reduction, flexibility, and resilience) and referred to related literature (Lee, 2014) to establish the social vulnerability index (SVI) framework. To make SVIs in line with Taipei's context, this study carried out the Delphi technique (including eight experts and converged after two rounds) and selected SVIs after considering the availability of the data. There are three sources of data: National Geographic Information System (NGIS) of Taiwan's
Fig. 1 Location of Taiwan and Districts of Taipei

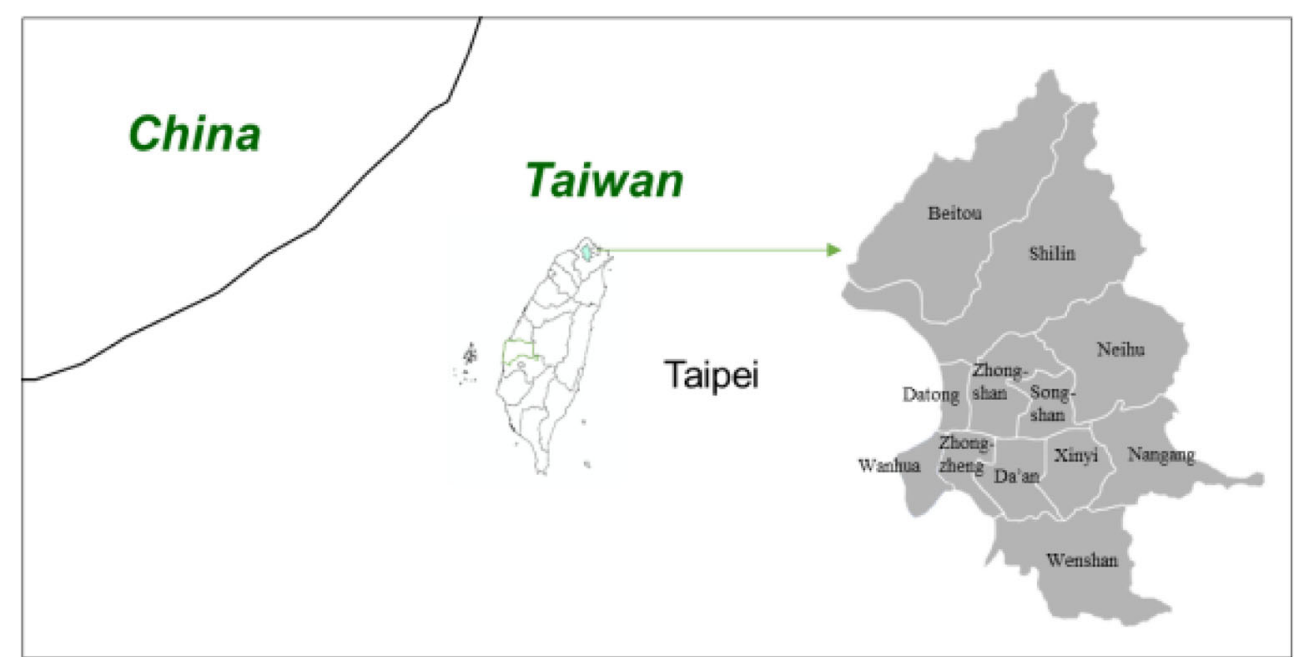


Table 1 Description of natural vulnerability data

\begin{tabular}{ll} 
Disaster potential maps & Content \\
\hline Flooding potential $(600 \mathrm{~mm} / 24 \mathrm{~h})$ & Potential range of flooding under different simulated rainfall conditions \\
Debris flow potential stream influence area & Debris flow potential stream and its influence area and warning value \\
Active fault & Active fault distribution \\
Tsunami overflow potential map & Tsunami overflow area \\
Detritus slide & Detritus slide area \\
Olistolith & Olistolith area \\
Dip slope & Dip slope area \\
Falling rocks & Falling rocks area \\
\hline
\end{tabular}

Ministry of the Interior, Department of Budget, Accounting and Statistics of Taipei City Government, and the related statistical units. The revised SVIs did not exhibit the four dimensions of SV of Taiwan's NCDR, and a total of 14 indicators were adopted to measure Taipei's SVI (Table 2).

\section{Integrated vulnerability}

Based on the above indicators and data calculation results, NV and SV are divided into three groups: high, medium, and low, and the ratio is classified into nine categories: low-low, lowmedium, low-high, medium-low, medium-medium, mediumhigh, high-low, high-medium, high-high. According to the IV rating from low to high, this study distinguishes five color layers (IV1 IV5), of which low NV-low SV is IV1; low NV-medium SV and medium NV-low SV are IV2; low NVhigh SV, high NV-low SV, and medium NV-medium SV are IV3; medium NV-high SV and high NV-medium SV are IV4; and high NV-high SV is IV5 (Table 3). IV1 is the lowest IV, with Beitou District. IV2 includes Nangang District, Shilin District, Wenshan District, Zhongshan District, and Neihu District. IV3 includes Zhongzheng District and Xinyi District. IV4 includes Wanhua District. IV5 has the highest integrated vulnerability, including Songshan District, Datong District and Da'an District.

The results show districts with high IV (high NV and high SV), including Datong, Da'an, and Songshan districts, are areas with high potential for impact in the face of climate change. These areas also have low disaster reduction, response, and recovery capabilities, which require priority attention. For example, Datong District has a high IV due to its weak disaster reduction and preparedness capacity and a low proportion of social welfare personnel. Since the exposure factor of SV includes industry and population size, districts with high urban development (high income and large populations) suffer more losses once disasters occur, resulting in high vulnerability (Bevacqua et al. 2019; Garcia-Ayllon 2018; IPCC 2014).

Table 2 Social vulnerability indicators

\begin{tabular}{|c|c|}
\hline Indicators & Calculation \\
\hline Population density & Total population of the district/total land area of the district (person/ $\mathrm{km}^{2}$ ) \\
\hline Dependency ratio & Population of old and young (over 65 and under 15)/total population of the district \\
\hline Elderly people living alone ratio & Elderly people living alone in the district/total population of the district \\
\hline Disability ratio & Number of people with disabilities in the district/total population of the district \\
\hline Social welfare staff ratio & Social welfare population in the district/total population of the district \\
\hline Number of medical institutions & Number of medical institutions in the district/number of medical institutions in Taipei \\
\hline Number of hospital beds & Number of hospital beds in the district/number of hospital beds in Taipei \\
\hline Primary industry population ratio & Primary industry population of neighborhood/primary industry population of Taipei \\
\hline Low-income household ratio & Number of low-income households/total number of households \\
\hline Budget ratio & District fiscal revenue/district fiscal revenue as a percentage of the population in the district \\
\hline Tap water supply ratio & Population with water supply in the district/total population of the district \\
\hline Older housing ratio & Number of completed housings in the district before 1970/total number of housings in the district \\
\hline Number of firefighters & Number of firefighters in the district/number of firefighters in Taipei \\
\hline $\begin{array}{l}\text { Ratio of disaster relief vehicles, } \\
\text { ambulances, and lifeboats }\end{array}$ & $\begin{array}{l}\text { Total number of disaster relief vehicles, ambulances, and lifeboats in the district/total number of disaster } \\
\text { relief vehicles, ambulances, and lifeboats in Taipei }\end{array}$ \\
\hline
\end{tabular}


Table 3 NV, SV, and IV classification

\begin{tabular}{|c|c|c|c|c|c|c|}
\hline \multirow{4}{*}{ Low } & SV & & & $\rightarrow$ & Layers & District \\
\hline & Low & Medium & High & & V1 & Beitou \\
\hline & Beitou & Nangang, Shilin, Wenshan & & & $\mathrm{V} 2$ & $\begin{array}{l}\text { Nangang, Shilin, Wenshan, Zhongshan, } \\
\text { Neihu }\end{array}$ \\
\hline & & & & & V3 & Xinyi, Zhongzheng \\
\hline Medium & Zhongshan, Neihu & Xinyi & Wanhua & & V4 & Wanhua \\
\hline High & Zhongzheng & & Songshan, Datong, Daan & & V5 & Songshan, Datong, Daan \\
\hline
\end{tabular}

Districts with low IV (low NV and low SV), such as Beitou District, have low potential impacts in the face of climate change and have high disaster mitigation, response, and recovery capacities. Nevertheless, when faced with the longterm impacts of climate change, there are still issues that must be faced. The NV of climate change in Zhongzheng District (high NV-low SV) is high, but it is less affected by changes in individual attributes factors. Residents in this area should pay attention to climate change adaptive behavior. Emphases should be placed on response works such as disaster prevention and relief and post-disaster adjustment.

Wanhua District (high IV) should cope with its weak SV in accordance with local conditions and carry out disaster reduction and prevention education to reduce the possibility of individual attributes collapse. This study will focus on two types of areas with extreme IV (high NV-high SV and low NV-low $\mathrm{SV}$ ) and explore the relationships between residents' place attachment and their individual attributes.

\section{Floods and study areas}

The target disaster of this study is floods. The natural vulnerability has eight layers, which are from Taiwan's NCDR (2016). According to NCDR, the flooding potential map is made through numerous simulations and modellings. The main cause of the flooding is rainfalls and is represented by $600 \mathrm{~mm}$ accumulated rainfalls in $24 \mathrm{~h}$ to simulate the trend and depth of flooding. The flooding trends and depths simulated by different accumulated rainfalls are not the same, and as the accumulated rainfalls increase, the area and depth of the flooding will expand. If the drainage system is poor, it may cause flooding.

The integrated vulnerabilities of this study are obtained by overlapping the natural vulnerability (eight disaster potential maps) of Taiwan's NCDR and the social vulnerability (14 variables) of Taipei. The flooding potential map is based on $600 \mathrm{~mm} / 24 \mathrm{~h}$. Since this study focuses on floods in Taipei, in addition to the integrated vulnerabilities, this study uses the flooding potential map of Taipei $(300 \mathrm{~mm} / \mathrm{h})$ to select the final research areas. The research areas selected after overlapping Taipei's flooding potential map can be in line with Taipei's context.
Based on the $300 \mathrm{~mm} / \mathrm{h}$ flooding potential map, more than half of Datong, Wanhua, and Zhongshan districts are potential flooded areas. Therefore, the study areas include Datong District and Wanhua District with high IV and more than half of the flooded area and Zhongshan District and Wenshan District with low IV and more than half of the flooded area (Fig. 2).

The selection of the study areas is similar to Tate et al. (2021) to explore the geographical distribution of social vulnerability of flood exposure, identify the most vulnerable places, and develop a set of social vulnerability indicators affected by flood exposure. Therefore, using Taipei's flooding potential map, two types of vulnerable areas are identified as the research areas through the integrated vulnerability overlapping. However, this integrated measurement only tells how many people were exposed, not who. Therefore, it is important to categorize the exposed population, because socially vulnerable people disproportionately live in flood-prone areas (Platt 1998). Most studies have applied general models of social vulnerability of different hazards and disaster stages. This general measure continues to be used to spatially analogize the social vulnerability of flood-prone areas (Roder et al. 2017). Although there is a clear difference between "establishing a social vulnerability model in flood-prone areas" and "establishing a flood-prone social vulnerability model" (Tate et al. 2021), this study belongs to the latter, analyzing the spatial, statistical, and process interactions between flood hazards and integrated vulnerability.

\section{Results}

\section{Individual attributes}

This study used stratified random sampling to select 600 respondents from four districts. During the questionnaire survey, two interviewers were recruited to assist the face-to-face survey. The survey was from December 1, 2018, to March 31, 2019. The failure rate was about $10 \%$.

The age distribution of the respondents is the largest for 21-25 years old (18.2\%), followed by those under 20 years old $(13.7 \%)$. Male and female respondents accounted for 
Fig. 2 Integrated vulnerability of districts in Taipei

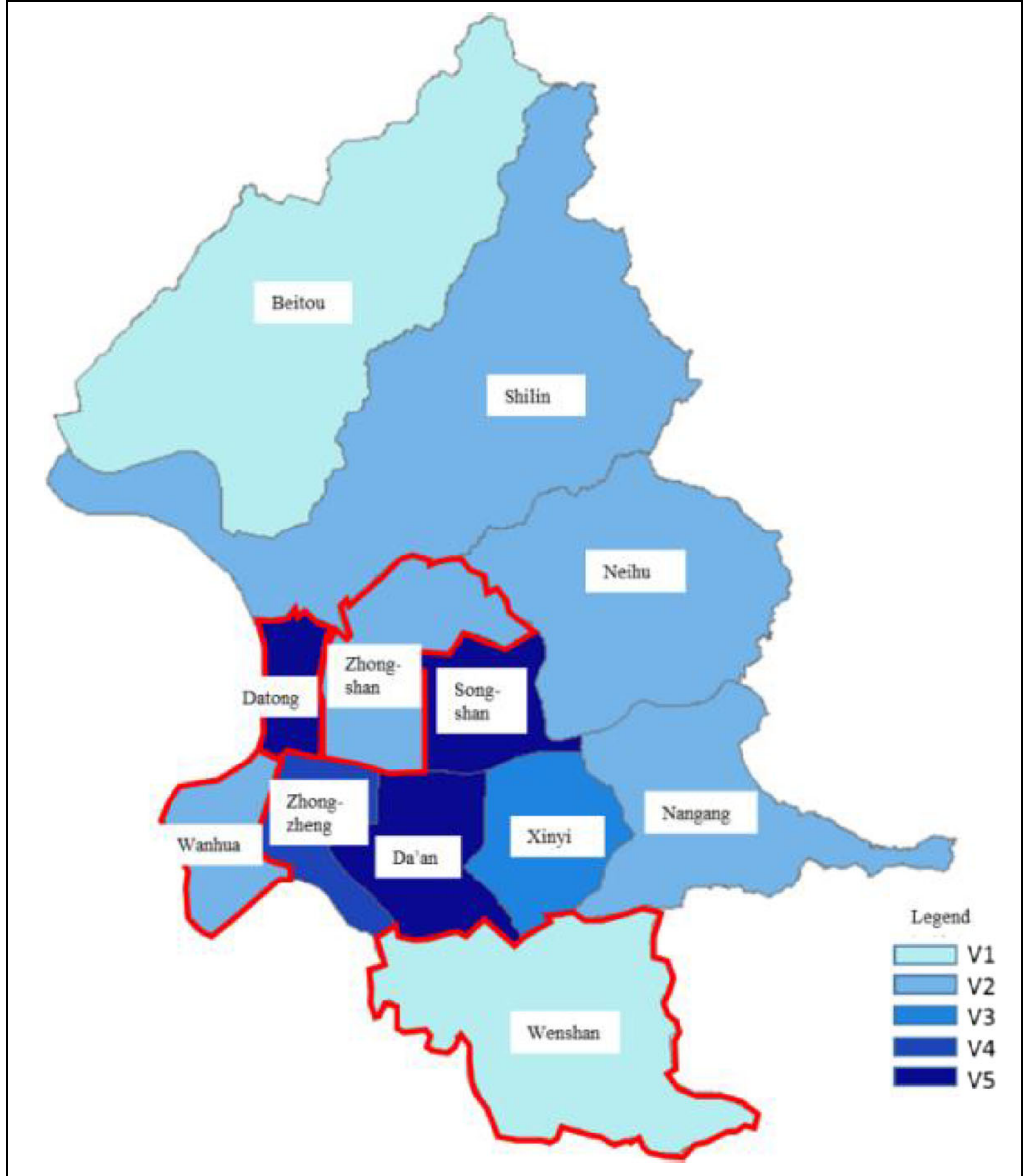

$45.2 \%$ and $54.8 \%$ respectively. In 2018 , the gender distribution of the four districts was $47.9 \%$ for males and $52.1 \%$ for females. The gender distribution of the sample is in line with the population of the four districts. The respondents' education distribution is highest in colleges and universities $(62.5 \%)$, followed by high school positions (18.8\%). More than 10 years of residence duration is the highest group of respondents $(61 \%)$, followed by $5-10$ years $(12 \%)$. Zero disaster experience is the largest $(66.2 \%)$, followed by one disaster experience (18\%) (Table 4).

\section{Relationships between individual attributes and place attachment}

The first section analyzes the correlation between respondents' age, residence duration, disaster experience, education, and place attachment in different IV districts. In the second part, place attachment is analyzed by factor analyses. The third part explores the correlation analyses between respondents' individual attributes in different IV districts and factors of place attachment. The place attachment questionnaire can be seen in Table 5 .

\section{Correlation between age and place attachment}

In different spatial contexts, whether respondents' place attachment is related to age has shown different results. De Dominicis et al. (2015), Gifford (2014), Gifford et al. (2009), and Schultz et al. (2014) pointed out the more the respondents understand risk prevention knowledge, the more they will adopt preventive behavior. "Age" may become the main cause of differences in risk perceptions and risk anxiety. Inadequate absorption of risk knowledge by the elderly, traditional myths, or differences in risk anxiety caused by the disaster experience of the elderly may cause "age" to affect preventive behavior and attitudes (Alshehri et al. 2016). The results show both high IV districts (Datong, Wanhua) and low IV districts (Zhongshan, Wenshan) are positively correlated (Table 6), indicating older respondents have higher place attachment, which is consistent with Jansen et al. (2020).

\section{Correlation between residence duration and place attachment}

Regardless of whether it is in a high IV district or a low IV district, place attachment is positively correlated with residence duration, corresponding to most research findings 
Table 4 Descriptive statistics $(n=600)$

\begin{tabular}{|c|c|}
\hline Variable & Category and percentage \\
\hline Age & $\begin{array}{l}\text { Under } 20(2.7 \%) ; 21-25(7.8 \%) ; 26-30(11 \%) ; 31-35(5.9 \%) ; 36-40(11.8 \%) ; 41-45(12.4 \%) ; 46-50(13.9 \%) ; 51-55(13.7 \%) \\
\quad 56-60(6.9 \%) ; 61-65(10.5 \%) \text {; over } 65(3.4 \%)\end{array}$ \\
\hline Education & $\begin{array}{l}\text { Under junior high school (1.2\%); junior high school (2.8\%); senior high school (21\%); college (43.3\%); master's degree (29.7\%); } \\
\text { doctoral degree (2\%) }\end{array}$ \\
\hline $\begin{array}{l}\text { Residence } \\
\text { duration }\end{array}$ & Under 1 year $(8 \%) ; 1-3$ years $(11 \%) ; 3-5$ years $(8 \%) ; 5-10$ years $(12 \%)$; over 10 years $(61 \%)$ \\
\hline $\begin{array}{l}\text { Disaster } \\
\quad \text { experience }\end{array}$ & $0(66.2 \%) ; 1(18 \%) ; 2$ (7.2\%); 3(4.3\%); $4(1 \%) ; 5(1.3 \%) ; 6(0.2 \%) ; 7$ (0.2\%); $8(0 \%) ; 9(1.7 \%)$ \\
\hline
\end{tabular}

(AlQahtany and Abubakar 2020; Jansen 2020; Lewicka 2011; Razem 2020). De Dominicis et al. (2015) examined the mediator effect of "neighborhood attachment" between risk perceptions and preventive behavior. Their results showed residence duration has a negative mediator effect of place attachment on risk perceptions and preventive behavior. In the case of high-risk perceptions, high neighborhood attachment will reduce people's intention to take preventive behavior and actual preventive behavior, which will increase the disaster risk.

However, our study suggests the correlation between residence duration and place attachment does not differ for different vulnerable districts. Respondents in the two different IV districts show the longer the residence duration, the greater the place attachment (Table 7).

\section{Correlation between disaster experience and place attachment}

Place attachment in high IV districts is positively correlated with disaster experience; place attachment in low IV districts is negatively correlated with disaster experience (Table 8). This study further analyzes the disaster experience and place attachment of all respondents, regardless of high or low IV. The results show a positive correlation, agreeing with Alshehri et al. (2016) that disaster experience is not a significant factor affecting perceptions and responsive behavior. Rather, the structure of different vulnerable areas is an important reason for the difference. Subsequent analyses are suggested to be divided into two groups (with and without an interaction) to explore the relationships between individual attributes and place attachments.

Table 5 Place attachment questionnaire

Questionnaire wordings

1. Current living environment makes me feel safe.

2. I don't think I belong to Taipei.

3. I feel I am not part of this district.

4. I feel I am not part of this neighborhood.

5. I will take the initiative to get close to and care for the environment in Taipei.

6. I will take the initiative to get close to and care for the environment in the district.

7. I will take the initiative to get close to and care for the environment in the neighborhood.

8. It is very difficult for me to leave Taipei.

9. It is very difficult for me to leave the district.

10. It's very difficult for me to leave the neighborhood.

11. Taipei is an ideal place.

12. My district is an ideal place.

13. My neighborhood is an ideal place.

14. Taipei where I live is a part of me and I am familiar with it.

15. The district where I live is part of me and I am familiar with it.

16. The neighborhood where I live is part of me and I am familiar with it.

\section{References}

Bonaiuto et al. (2016), Raymond and Brown (2010),

Michel-Guillou et al. (2016)

Scannell and Gifford (2014), Bonaiuto et al. (2016), Scannell and Gifford

Raymond and Brown (2010), Giuliani (2003), Uzzell (2000)

De Dominicis et al. (2015), Hidalgo and Hernandez (2001),

Lewicka (2011), Paton et al. (2008)

De Dominicis et al. (2015), Raymond and Brown (2010),

Michel-Guillou et al. (2016), Paton et al. (2008)

De Dominicis et al. (2015), Hidalgo and Hernandez (2001), Raymond and Brown (2010), Lewicka (2011), Giuliani (2003), Uzzell (2000) 
Table 6 Correlation between age and place attachment

Place attachment

\begin{tabular}{lll}
\cline { 2 - 2 } IV & High IV (Datong, Wanhua) & Low IV (Zhongshan, Wenshan) \\
\hline Age + & + \\
\hline
\end{tabular}

Note: “+” means positive correlation $(p<0.1)$; “-” means negative correlation $(p<0.1)$; "blank" means no correlation $(p>0.1)$

\section{Correlation of education and place attachment}

There is no correlation between place attachment and education, regardless of whether it is a high IV district or a low IV district (Table 9). Similarly, further analyses of education and place attachment of all respondents show no correlation. This result differs from Jansen (2020) and Lewicka (2011) that education is negatively correlated with place attachment and is worthy of future exploration.

\section{Place attachment factor analysis}

Concerning the relationship between place attachment and risk perceptions or intentions, no consistent conclusions can be reached (e.g., De Dominicis et al. 2015; Mishra et al. 2010; Ruiz and Hernández 2014). Restated, place attachment concepts are diverse and complex (Bonaiuto et al. 2016; De Dominicis et al. 2015). Therefore, different areas and individual attributes may deliver different place attachments (Bonaiuto et al. 2016; Casakin et al. 2015; Schilar and Keskitalo 2018). The literature suggests place attachment has different factors and factor analyses should be conducted.

There are 16 questions related to place attachment in this study (Table 5). This study first carries out factor analyses to simplify the questions and then conducts correlation analyses. The 16 questions are reduced to dimensions using KMO and the Bartlett test, and the values are between 0 and 1 . The larger the value, the more common factors between the variables, and the more suitable it is for factor analysis.

The criterion of KMO value is $0.9 \leqq \mathrm{KMO}$ is very suitable for factor analysis; $0.8 \leqq \mathrm{KMO} \leqq 0.9$ is good; $0.7 \leqq \mathrm{KMO} \leqq$ 0.8 is not bad; $0.6 \leqq \mathrm{KMO} \leqq 0.7$ normal; $0.5 \leqq \mathrm{KMO} \leqq 0.6$ is not suitable; KMO $\leqq 0.5$ cannot be used (Bartlett 1989). According to Table 10, the KMO value of 0.749 for this study is greater than 0.5 , which is suitable for factor analysis.
According to Table 11, the 16 items can come out with four factors.

According to Table 12, place attachment questions 1, 11, 12, 13, 14, 15, and 16 are a factor, "security." Questions 5, 6, and 7 are a factor, "familiarity." Questions 2, 3, and 4 are a factor, "belongingness." Questions 8, 9, and 10 are a factor, "rootedness."

Subsequent analyses will be divided into two groups based on the relationships between individual attributes and place attachment. "Age" and "residential duration" that do not show an interaction are a group. "Disaster experience" that shows an interaction and the unrelated "education" are a group.

\section{A. High/low IV districts showing an interaction}

(a) Correlation between age and place attachment

"Security" and "age" are not correlated, regardless of whether they are in high IV districts or low IV districts. "Familiarity" is negatively correlated with "age" in high IV districts and has no correlation in low IV districts. "Belongingness" is positively correlated with age in high IV districts but has no correlation in low IV districts. The relationship between "rootedness" and age is the same as the relationship with age before the factor analysis of place attachment, which is positively correlated regardless of high or low IV (Table 13).

Regarding the exploration of age and place attachment, "security," "familiarity," and "belongingness" have different results from those before factor analyses. It is suggested once these three factors are involved, factor analyses should be carried out in different vulnerable areas.

(b) Correlation between residence duration and place attachment

"Security" and residence duration show no correlation in high IV districts but a positive correlation in low IV districts. "Rootedness" has no correlation with residence duration in high IV districts but a positive correlation in low IV districts. Note, "familiarity," "belongingness," and residence duration are positively correlated in areas with high or low IV, which is the same as the results before factor analyses (Table 14).

As for "security" and "rootedness," the results differ from those before the factor analyses. Therefore, if these two factors
Table 7 Correlation between residence duration and place attachment

\begin{tabular}{lll}
\hline & \multicolumn{2}{l}{ Place attachment } \\
\cline { 2 - 3 } IV & High IV (Datong, Wanhua) & Low IV (Zhongshan, Wenshan) \\
\hline Residence duration & + \\
\hline $\begin{array}{l}\text { Note: “+” means positive correlation }(p<0.1) ; \text { "-” means negative correlation }(p<0.1) ; \text { "blank" means no } \\
\text { correlation }(p>0.1)\end{array}$
\end{tabular}


Table 8 Correlation between the number of disaster experiences and place attachment

\begin{tabular}{lll}
\hline & \multicolumn{2}{l}{ Place attachment } \\
\cline { 2 - 3 } IV & High IV (Datong, Wanhua) & Low IV (Zhongshan, Wenshan) \\
\hline Disaster experience & + & - \\
\hline
\end{tabular}

Note: “+” means positive correlation $(p<0.1)$; “-” means negative correlation $(p<0.1)$; "blank" means no correlation $(p>0.1)$ are involved in future studies, they should be analyzed in different vulnerability areas.

B. High/low IV districts showing no interaction and no correlation

(a) Correlation between disaster experience and place attachment

"Belongingness" is the same as the relationship between place attachment and disaster experience before the factor analysis, which shows a positive correlation in high IV districts and a negative correlation in the low IV districts. The relationship between "security," "rootedness," and disaster experience is not correlated in high IV districts, whereas it is negatively correlated in low IV districts. The relationship between "familiarity" and disaster experience is positively correlated in high IV districts and shows no correlation in low IV districts (Table 15).

These results show "security," "familiarity," and "rootedness" have different results from before the factor analysis. If the three factors are involved in future studies, they should be examined in detail in different vulnerable areas.

(b) Correlation between education and place attachment

"Security" and "rootedness" have no correlation with education in high IV districts and a positive correlation in low IV districts. "Familiarity" is positively correlated in high IV districts and has no correlation in low IV districts. "Belongingness" and education are positively correlated, regardless of whether it is in high or low IV districts (Table 16).

In terms of education, no place attachment factors have the same relationships as the results before factor analyses. Research on the relationships between education and place attachment should be carefully examined in different vulnerability areas.

\section{Summary}

This section first examines the correlations between individual attributes and place attachment and then performs factor analyses on place attachment. Furthermore, correlation analyses are conducted between each individual attribute and the fourplace attachment factors after factor analyses. In addition to finding out whether each variable is related to place attachment under different factors, the research results also compare the results before and after factor analyses to elucidate whether differences exist in place attachment factors.

As the research results indicate when examining "age" and place attachment, "rootedness" can be the main reference factor; when exploring "residence duration" and place attachment, "familiarity" and "belongingness" can be the main reference factor. When elucidating "disaster experience" and place attachment, "belongingness" can be the main reference factor; when discussing "education" and place attachment, there is no major reference factor (Table 17).

These findings suggest the main factors and topics that can be referred to when exploring the relationships between individual attributes and place attachment. Individually, the main reference factors do not show certain rules. Among the four factors "security," "familiarity," "belongingness," and "rootedness" obtained from place attachment factor analyses, no factors specifically affect the overall place attachment. As to the four individual attributes, there is no certain rule between each factor and the overall place attachment. It is suggested research on place attachment requires place attachment factor analyses to obtain detailed and thorough research results.

\section{Mediator effect}

After examining the correlation relationships among individual attributes and place attachment, this study further adopts
Table 9 Correlation between education level and place attachment

\begin{tabular}{|c|c|c|}
\hline \multirow[b]{2}{*}{ IV } & \multicolumn{2}{|l|}{ Place attachment } \\
\hline & High IV (Datong, Wanhua) & Low IV (Zhongshan, Wenshan) \\
\hline Edu & & \\
\hline
\end{tabular}


Table $10 \mathrm{KMO}$ and Bartlett test

\begin{tabular}{lll} 
Kaiser-Meyer-Olkin measure of sampling adequacy & .749 \\
\hline $\begin{array}{lll}\text { Bartlett test of } \\
\text { sphericity }\end{array}$ & Chi-square test & 1853.271 \\
& df & 120 \\
& Significance & .000 \\
\hline
\end{tabular}

three-step regression models to explore the mediator effect between risk experience and place attachment. The first step explores the relationship between flood risk perception and coping behavior intentions, the second step explores the relationship between place attachment and coping behavior intentions, and the third step explores the interaction effect of place attachment in the relationship between flood risk perception and coping behavior intentions.

\section{Datong}

As shown in Table 18, in terms of direct effects, the path coefficient of "attitude $\rightarrow$ place attachment" reaches a significantly negative value $(\beta=-.293, p<.05)$. This means when Datong residents' attitudes are more positive, the degree of place attachment is lower, which corresponds to De Dominicis et al.'s (2015) finding that place attachment has a negative mediator effect on attitude. In addition, the path coefficient of "place attachment $\rightarrow$ coping behavior" reaches a significantly positive value $(\beta=.291, p<.05)$. This means
Table 12 Component matrix after rotation

\begin{tabular}{lllll}
\hline & Factor & & & \\
\cline { 2 - 5 } & 1 & 2 & 3 & 4 \\
\hline 14 & .828 & .090 & -.095 & .067 \\
15 & .761 & .325 & -.213 & .063 \\
16 & .685 & .224 & -.198 & .026 \\
1 & .675 & -.140 & -.056 & -.081 \\
12 & .653 & .172 & -.210 & .355 \\
13 & .575 & .247 & -.179 & .340 \\
11 & .566 & .104 & -.111 & .409 \\
6 & .163 & .902 & -.171 & .166 \\
5 & .139 & .891 & -.153 & .127 \\
7 & .161 & .873 & -.216 & .177 \\
3 & -.214 & -.246 & .906 & -.107 \\
2 & -.262 & -.037 & .871 & .013 \\
4 & -.134 & -.299 & .856 & -.113 \\
9 & .065 & .207 & -.055 & .912 \\
10 & -.015 & .182 & .009 & .859 \\
8 & .236 & .014 & -.093 & .706 \\
\hline
\end{tabular}

when Datong residents have a higher degree of place attachment, the degree of coping behavior will be higher. As for the other path coefficients, they do not reach a significant level, indicating no direct effect.

Table 11 Explanation of total variation

\begin{tabular}{|c|c|c|c|c|c|c|c|c|c|}
\hline \multicolumn{4}{|c|}{ Eigenvalues } & \multicolumn{3}{|c|}{ Factor loading } & \multicolumn{3}{|c|}{ Rotation sums of squared loadings } \\
\hline & Total & Variance $\%$ & Accumulated $\%$ & Total & Variance $\%$ & Accumulated \% & Total & Variance $\%$ & Accumulated \% \\
\hline 1 & 6.252 & 39.072 & 39.072 & 6.252 & 39.072 & 39.072 & 3.530 & 22.061 & 22.061 \\
\hline 2 & 2.115 & 13.221 & 52.293 & 2.115 & 13.221 & 52.293 & 2.882 & 18.010 & 40.070 \\
\hline 3 & 1.913 & 11.956 & 64.249 & 1.913 & 11.956 & 64.249 & 2.606 & 16.290 & 56.360 \\
\hline 4 & 1.329 & 8.306 & 72.555 & 1.329 & 8.306 & 72.555 & 2.591 & 16.195 & 72.555 \\
\hline 5 & .996 & 6.224 & 78.779 & & & & & & \\
\hline 6 & .742 & 4.636 & 83.415 & & & & & & \\
\hline 7 & .673 & 4.209 & 87.625 & & & & & & \\
\hline 8 & .532 & 3.324 & 90.949 & & & & & & \\
\hline 9 & .385 & 2.409 & 93.358 & & & & & & \\
\hline 10 & .287 & 1.792 & 95.150 & & & & & & \\
\hline 11 & .231 & 1.442 & 96.593 & & & & & & \\
\hline 12 & .168 & 1.052 & 97.644 & & & & & & \\
\hline 13 & .142 & .889 & 98.533 & & & & & & \\
\hline 14 & .100 & .623 & 99.157 & & & & & & \\
\hline 15 & .084 & .525 & 99.682 & & & & & & \\
\hline 16 & .051 & .318 & 100.00 & & & & & & \\
\hline
\end{tabular}

Extraction method: principal component analysis 
Table 13 Correlation between age and different factors of place attachment in different vulnerable areas

\begin{tabular}{lll}
\hline \multicolumn{3}{c}{ Place attachment } \\
\cline { 2 - 3 } IV & High IV (Datong, Wanhua) & $\begin{array}{l}\text { Low IV (Zhongshan, } \\
\text { Wenshan) }\end{array}$ \\
\hline Before factor analysis & \\
Age & + & + \\
After factor analysis & \\
Security & & \\
Familiarity & - & + \\
Belongingness & + & + \\
Rootedness & + & \\
\hline
\end{tabular}

Note: "+" means positive correlation $(p<0.1)$; “-” means negative correlation $(p<0.1)$; "blank" means no correlation $(p>0.1)$

\section{Wanhua}

As shown in Table 19, in terms of direct effects, the path coefficient of "perception $\rightarrow$ coping behavior" reaches a significant positive value $(\beta=.422, p<.01)$. This means when Wanhua respondents have a better perception, the degree of coping behavior will be higher. As for the other path coefficients, they do not reach a significant level, indicating no direct effect. In terms of indirect effects, according to Sobel's test, the results of the two mediation paths do not reach a significant level $(p>.05)$, indicating perception or attitude of Wanhua respondents do not have a significant effect on coping behavior through the place attachment.

\section{Zhongshan}

As shown in Table 20, in terms of direct effects, the path coefficient of "perception $\rightarrow$ coping behavior" reaches a

Table 14 Correlation between residence duration and different factors of place attachment in different vulnerable areas

\begin{tabular}{lll}
\hline \multicolumn{3}{l}{ Place attachment } \\
\cline { 2 - 3 } IV & High IV (Datong, Wanhua) & $\begin{array}{l}\text { Low IV (Zhongshan, } \\
\text { Wenshan) }\end{array}$ \\
\hline Before factor analysis & \\
Residence duration & + \\
After factor analysis & \\
Security & & + \\
Familiarity & & + \\
Belongingness & + & + \\
Rootedness & + & +
\end{tabular}

Note: “+” means positive correlation $(p<0.1)$; “-” means negative correlation $(p<0.1)$; "blank" means no correlation $(p>0.1)$
Table 15 Correlation of disaster experience and different factors of place attachment in different vulnerable areas

\begin{tabular}{lll}
\hline \multicolumn{3}{l}{ Place attachment } \\
\cline { 2 - 3 } IV & High IV (Datong, Wanhua) & $\begin{array}{l}\text { Low IV (Zhongshan, } \\
\text { Wenshan) }\end{array}$ \\
\hline Before factor analysis & \\
Disaster experience & + & - \\
After factor analysis & - \\
Security & + & - \\
Familiarity & + & - \\
Belongingness & + & \\
Rootedness & & - \\
\hline
\end{tabular}

Note: "+" means positive correlation $(p<0.1)$; “-” means negative correlation $(p<0.1)$; "blank" means no correlation $(p>0.1)$

significant positive value $(\beta=.416, p<.01)$, indicating when Zhongshan respondents have better perception performance, the degree of coping behavior will be higher. In addition, the path coefficient of "attitude $\rightarrow$ coping behavior" also reaches a significant positive value $(\beta=.180, p<.05)$, meaning the more positive the attitude of Zhongshan respondents, the greater the degree of response behavior. As for the other path coefficients, they do not reach a significant level, indicating no direct effect. In terms of indirect effects, according to Sobel's test, the results of the two mediation paths do not reach a significant level $(p>.05)$, meaning perceptions or attitude of Zhongshan respondents do not have a significant effect on coping behavior through the place attachment.

\section{Wenshan}

As shown in Table 21, in terms of direct effects, the path coefficient of "perception $\rightarrow$ coping behavior" reaches a

Table 16 Correlation between education and different factors of place attachment in different vulnerable areas

\begin{tabular}{lll}
\hline \multicolumn{3}{c}{ Place attachment } \\
\cline { 2 - 3 } IV $\quad$ High IV (Datong, Wanhua) & $\begin{array}{l}\text { Low IV (Zhongshan, } \\
\text { Wenshan) }\end{array}$ \\
\hline Before factor analysis & \\
Education & \\
After factor analysis & + \\
Security & & \\
Familiarity & + & + \\
Belongingness & + & + \\
Rootedness &
\end{tabular}

Note: "+" means positive correlation $(p<0.1)$; “-" means negative correlation $(p<0.1)$; "blank" means no correlation $(p>0.1)$ 
Table 17 Factors with the same results before and after factor analyses

\begin{tabular}{lllll}
\hline Variables & Age & Residence duration & Disasters experience & Education \\
\hline Factors with the same results & Rootedness & Familiarity & Belongingness & None \\
& & Belongingness & & \\
\hline
\end{tabular}

significantly positive value $(\beta=.330, p<.05)$, meaning the better the cognitive performance of Wenshan respondents, the higher the degree of coping behavior. As for the other path coefficients, they do not reach a significant level, indicating no direct effect. In terms of indirect effects, according to Sobel's test, the results of the two intermediary paths do not reach a significant level $(p>.05)$, meaning the perception or attitude of Wenshan respondents do not have a significant effect on coping behavior through the place attachment.

\section{Summary}

According to the paths of "perception $\rightarrow$ place attachment $\rightarrow$ coping behavior" and "attitude $\rightarrow$ place attachment $\rightarrow$ coping behavior," it can be suggested place attachment does not act as a mediator. The research results indicate the relationships in the same area may differ. For example, in the same district, there may be areas where disasters are more likely to occur and areas which are relatively safe. Furthermore, most of the results indicate place attachment does not have a significant effect. A possible reason could be this study did not differentiate different geographical scales for measuring place attachment, making the internal differences unclear. Follow-up studies can differentiate different geographical scales to elucidate the place attachment to obtain more detailed research results.

\section{Conclusions and suggestions}

Studies have pointed out there may be significant differences in place attachments in the same settlement. Although this may be related to residence duration, residence role, or participation in the community, we must remember this local/newcomer division should not be exaggerated (van Veelen and Haggett 2017). Place attachment cannot be determined solely based on the characteristics of the site or place. It may be more valuable to examine how individual attributes affect a certain place attachment. For example, a strong place attachment is related to a strong acceptance of the responsibility of protecting the environment and personal norms (Zhang et al. 2017). In contrast, the development of the Indonesian volcanic sub-culture became a motivation for highly attached residents to refuse to evacuate and stay in these dangerous areas (Lavigne et al. 2008).

The correlation analysis between age and place attachment shows a positive correlation in both high IV districts (Datong, Wanhua) and low IV districts (Zhongshan, Wenshan), which is consistent with Jansen et al. (2020). Analysis of the correlation between residence duration and place attachment shows a positive correlation in both high and low IV districts. These results are compared with Su et al. (2017) that in the process of risk perceptions, there are other mediating variables between disaster experience and individual self-efficacy, making past

Table 18 Datong structural coefficients

\begin{tabular}{|c|c|c|c|c|c|}
\hline Path & $B$ & SE & $t$ & $p$ & $\beta$ \\
\hline \multicolumn{6}{|l|}{ Direct effect } \\
\hline Perception $\rightarrow$ place attachment & 0.071 & 0.058 & 1.225 & .221 & .172 \\
\hline Attitude $\rightarrow$ place attachment & -0.119 & 0.057 & $-2.097 *$ & .036 & -.293 \\
\hline Perception $\rightarrow$ coping behavior & 0.094 & 0.070 & 1.341 & .180 & .179 \\
\hline \multirow[t]{2}{*}{ Attitude $\rightarrow$ coping behavior place attachment $\rightarrow$ coping behavior } & 0.119 & 0.064 & 1.851 & .064 & .230 \\
\hline & 0.370 & 0.169 & $2.193 *$ & .028 & .291 \\
\hline \multicolumn{6}{|l|}{ Indirect effect } \\
\hline Perception $\rightarrow$ place attachment $\rightarrow$ coping behavior & 0.026 & 0.025 & 1.069 & .285 & .050 \\
\hline Attitude $\rightarrow$ place attachment $\rightarrow$ coping behavior & -0.044 & 0.029 & -1.516 & .130 & -.085 \\
\hline
\end{tabular}

$B$, unstandardized coefficient; $S E$, standard error; $\beta$, standardization factor

$* p<.05$

$* * p<.01$

$p<.001$ 
Table 19 Wanhua structural coefficients

\begin{tabular}{|c|c|c|c|c|c|}
\hline Path & $B$ & SE & $t$ & $p$ & $\beta$ \\
\hline \multicolumn{6}{|l|}{ Direct effect } \\
\hline Perception $\rightarrow$ place attachment & -0.023 & 0.026 & -0.859 & .390 & -.132 \\
\hline Attitude $\rightarrow$ place attachment & 0.006 & 0.015 & 0.412 & .681 & .047 \\
\hline Perception $\rightarrow$ coping behavior & 0.281 & 0.091 & $3.097 * *$ & .002 & .422 \\
\hline \multirow[t]{2}{*}{ Attitude $\rightarrow$ coping behavior place attachment $\rightarrow$ coping behavior } & 0.094 & 0.053 & 1.778 & .075 & .187 \\
\hline & 0.940 & 0.764 & 1.231 & .218 & .241 \\
\hline \multicolumn{6}{|l|}{ Indirect effect } \\
\hline Perception $\rightarrow$ place attachment $\rightarrow$ coping behavior & -0.021 & 0.030 & -0.705 & .481 & -.032 \\
\hline Attitude $\rightarrow$ place attachment $\rightarrow$ coping behavior & .006 & 0.015 & 0.390 & .696 & .011 \\
\hline
\end{tabular}

$B$, unstandardized coefficient; $S E$, standard error; $\beta$, standardization factor

$* p<.05$

$* * p<.01$

$* * * p<.001$

flood experience relatively unimportant. AlQahtany and Abubakar (2020) suggest there is a statistically significant relationship between respondents' sense of residence attachment and their worries about disaster risks, and a statistically significant relationship between the length of residence and personal responsibility.

Follow-up studies can refer to Tate et al. (2021) to calculate the area of people exposed to floods in each census area and to carry out bivariate LISA to map the spatial clustering of extreme flood exposure and surrounding integrated vulnerability. In addition to the differences in the individual attributes, this study suggests since the concepts of risk perceptions, coping behavior intention, and place attachment are complex, there are significant differences in positive or negative correlation. In the research areas, factor analyses of place attachment and differentiation of geographical scales should be carried out. For example, different geographical scales of neighborhood, district, and city should be distinguished to explore the relationship between floods, vulnerability, and climate change. Only by so doing, can we accurately reflect on various relationships and propose appropriate coping strategies for floods (and other environmental disasters).

Disaster experience and place attachment are positively correlated. After further dividing into high and low IV districts, place attachment in high IV districts is positively correlated with disaster experience, and place attachment in low IV districts is negatively correlated with disaster experience, pointing to an interactive relationship. Previous studies such as Clarke et al. (2018) and Song et al. (2019) used the interactive relationship to explain the relationship between place attachment and responsive behavior. Furthermore,

Table 20 Zhongshan structural coefficients

\begin{tabular}{|c|c|c|c|c|c|}
\hline Path & $\mathrm{B}$ & SE & $t$ & $p$ & $\beta$ \\
\hline \multicolumn{6}{|l|}{ Direct effect } \\
\hline Perception $\rightarrow$ place attachment & 0.057 & 0.042 & 1.366 & .172 & .199 \\
\hline Attitude $\rightarrow$ place attachment & 0.015 & 0.018 & 0.807 & .420 & .081 \\
\hline Perception $\rightarrow$ coping behavior & 0.338 & 0.110 & $3.061 * *$ & .002 & .416 \\
\hline \multirow[t]{2}{*}{ Attitude $\rightarrow$ coping behavior place attachment $\rightarrow$ coping behavior } & 0.093 & 0.047 & $1.977^{*}$ & .048 & .180 \\
\hline & 0.565 & 0.372 & 1.518 & .129 & .199 \\
\hline \multicolumn{6}{|l|}{ Indirect effect } \\
\hline Perception $\rightarrow$ place attachment $\rightarrow$ coping behavior & 0.032 & 0.032 & 1.015 & .310 & .040 \\
\hline Attitude $\rightarrow$ place attachment $\rightarrow$ coping behavior & 0.008 & 0.012 & 0.712 & .476 & .016 \\
\hline
\end{tabular}

$B$, unstandardized coefficient; $S E$, standard error; $\beta$, standardization factor

$* p<.05$

$* * p<.01$

$* * * p<.001$ 
Table 21 Wenshan structural coefficients

\begin{tabular}{|c|c|c|c|c|c|}
\hline Path & $B$ & SE & $t$ & $p$ & $\beta$ \\
\hline \multicolumn{6}{|l|}{ Direct effect } \\
\hline Perception $\rightarrow$ place attachment & -0.006 & 0.014 & -0.444 & .657 & -.070 \\
\hline Attitude $\rightarrow$ place attachment & 0.000 & 0.010 & -0.019 & .985 & -.002 \\
\hline Perception $\rightarrow$ coping behavior & 0.148 & 0.069 & $2.139 *$ & .032 & .330 \\
\hline \multirow[t]{2}{*}{ Attitude $\rightarrow$ coping behavior place attachment $\rightarrow$ coping behavior } & -0.007 & 0.050 & -0.138 & .890 & -.017 \\
\hline & 1.875 & 2.471 & 0.759 & .448 & .365 \\
\hline \multicolumn{6}{|l|}{ Indirect effect } \\
\hline Perception $\rightarrow$ place attachment $\rightarrow$ coping behavior & -0.012 & 0.030 & -0.383 & .702 & -.026 \\
\hline Attitude $\rightarrow$ place attachment $\rightarrow$ coping behavior & 0.000 & 0.019 & -0.019 & .985 & -.001 \\
\hline
\end{tabular}

$B$, unstandardized coefficient; $S E$, standard error; $\beta$, standardization factor

$* p<.05$

$* * p<.01$

$* * * p<.001$

corresponding to Alshehri et al. (2016), disaster experience is not a factor affecting perceptions and coping behavior. In contrast, areas with different vulnerabilities are important reasons for the differences. In this study, education is not correlated to place attachment, which is inconsistent with Jansen (2020) and Lewicka (2011) (with a negative correlation) and is worth further exploration. Some future research topics are as follows.

1. Based on this study and other research findings, the NV and SV of a region, as well as people's risk perceptions and place attachment, have positive benefits for planning disaster prevention communities, sustainable communities, and resilient communities (Gu et al. 2018; Marigi 2017; Mavromatidi et al. 2018; Razem 2020). In the future, cities and/or countries should continue to explore the relationship between local vulnerability and climate change disasters.

2. Chan et al. (2019) and the findings of this study indicate the cross-sectional nature of the research makes the research inferences limited to correlation relationships, not causal relationships (Alshehri et al. 2016). Long-term follow-up studies are needed to address trends and changes in community perceptions and behavior, which is important to ensure relevant, appropriate, and effective family protection measures are in place to cope with future extreme weather events.

3. The goals of climate change adaptation/mitigation and building resilient cities require collaborated and concerted efforts of the public and private sectors. Improved knowledge and awareness of disaster risk, as well as increased coping capacities (Malik et al. 2019; Schipper and Pelling 2006), can make the government's disaster reduction policies and interventions more effective, thereby strengthening participatory disaster risk management (Alshehri et al. 2016; Brown et al. 2018; Wang et al. 2019).

4. Research on place attachment includes numerous contexts and disciplines. When examining issues related to community development programs, we should adapt to different local issues: the relationships between individual attributes and place attachment and how these issues affect perceptions of change. van Veelen and Haggett (2017) argue place attachment is not static. In the future, the process of how social attachment "becomes" a part of the "local" should be addressed. Since the formation and structure of place attachments are complex, factor analyses should be carried out to obtain detailed and realistic results in different vulnerable areas.

5. This study is designed for elucidating "floods" in Taipei and examines the variables in the statistical models on a rolling basis. The research findings can help draft climate change policies and at the same time remind the government to pay attention to regional differences and differences in individual attributes (socioeconomic background, place attachment, etc.). Vulnerability areas derived from this study can be adopted to set mitigation priorities. For example, areas with similar disaster conditions or individual attributes may be reasonable partners for sharing knowledge and best practices (Chang and Chou 2018).

6. Coinciding with the COVID-19 pandemic in 2020, the pandemic has had a major impact on lifestyles, work patterns, space definitions, and even one's own lives and properties worldwide. Practically, in addition to the tangible climate-related disasters, the causal relationships of the non-tangible pandemic with risk perceptions and attitudes, place attachments, coping behaviors, and 
individual attributes are worth examining. To what extent these relationships affect policies for public and private sectors are also issues worth exploring.

Author contributions Prof. Yung-Jaan Lee is responsible for theoretical construction, research methods, literature review, and final manuscript editing. Ms. Shih-Ying Lin is responsible for data collection, statistical analyses, and the first draft of the manuscript. Prof. Lee and Ms. Lin read and approved the final manuscript.

Funding The authors would like to thank the Ministry of Science and Technology of the Republic of China, Taiwan, for financially supporting this research under contract MOST107-2410-H-170-001-MY2.

Data availability The datasets used and analyzed during the current study are available from the corresponding author on reasonable request.

\section{Declarations}

Ethics approval and consent to participate The authors confirm this study was approved by the Ministry of Science and Technology of the Republic of China, Taiwan for ethics approval and consent to participate. Consent for publication is not applicable.

Competing interests The authors declare no competing interests.

\section{References}

Adger WN (2006) Vulnerability. Glob Environ Chang 16(3):268-281

AlQahtany AM, Abubakar IR (2020) Public perception and attitudes to disaster risks in a coastal metropolis of Saudi Arabia. Int J Disaster Risk Reduct 44(2020):101422

Alshehri SA, Rezgui Y, Li H (2016) Public perceptions and attitudes to biological risks: Saudi Arabia and regional perspectives. Disasters 40(4):799-815

Babcicky P, Seebauer S (2017) The two faces of social capital in private flood mitigation: Opposing effects on risk perception, self-efficacy and coping capacity. J Risk Res 20(8):1017-1037

Bartlett KA (1989) Structural equations with latent variables. John Wiley and Sons, New York

Bennett NJ, Dearden P, Peredo AM (2014) Vulnerability to multiple stressors in coastal communities: a study of the Andaman coast of Thailand. Clim Dev. https://doi.org/10.1080/175655292014886993

Bevacqua E, Maraun D, Vousdoukas MI et al (2019) Higher probability of compound flooding from precipitation and storm surge in Europe under anthropogenic climate change. Sci Adv 5(9):eaaw5531. https://doi.org/10.1126/sciadvaaw5531

Bollettino V, Alcayna T, Enriquez K, Vinck P (2018) Perceptions of disaster resilience and preparedness in the Philippines. Harvard University, Cambridge

Bonaiuto M, Alves S, De Dominicis S, Petruccelli I (2016) Place attachment and natural environmental risk: research review and agenda. $\mathrm{J}$ Environ Psychol 48(2016):33-53

Brown B, Perkins DD, Brown G (2003) Place attachment in a revitalizing neighborhood: individual and block levels of analysis. J Environ Psychol 23(3):259-271

Brown P, Daigneault AJ, Tjernström E, Zou W (2018) Natural disasters, social protection, and risk perceptions. World Dev 104:310-325

Casakin H, Hernández B, Ruiz C (2015) Place attachment and place identity in Israeli cities: the influence of city size. Cities 42:224-230
Chan EYY, Man AYT, Lam HCY et al (2019) Is urban household emergency preparedness associated with short-term impact reduction after a super typhoon in subtropical city? Int J Environ Res Public Health 16:596. https://doi.org/10.3390/ijerph16040596

Chan EYY, Yue J, Lee P, Wang SS (2016) Socio-demographic predictors for urban community disaster health risk perception and household based preparedness in a Chinese urban city. PLoS Curr 8:1-11

Chan NW (1995) Choice and constraints in floodplain occupation: the influence of structural factors on residential location in Peninsular Malaysia. Disasters 19(4):287-307

Chang HM, Chou CL (2018) A study of cyclists activity involvement, place attachment, satisfaction and loyalty. Asian J Environ Ecol 5(3): $1-10$

Chen LC, Kuo SY, Chou KT, Lin TL, Lin LY, Lin TH, Hing HC (2018) Sustainability science plan of integrated risk governance of climate change disaster impact. J Taiwan Land Research 21(2):153-180 (in Chinese)

Clarke D, Murphy C, Lorenzoni I (2018) Place attachment, disruption and transformative adaptation. J Environ Psychol 55:81-89

Cogut G, Webster N, Marans RW, Callerwaert J (2019) Links between sustainability-related awareness and behavior: the moderating role of engagement. Int J Sustain High Educ 20(7):1240-1257

Convergences (2019) Sustainable solutions barometer. Convergences, Paris

Danish HST, Baloch MA et al (2019) Linking economic growth and ecological footprint through human capital and biocapacity. Sustain Cities Soc 47:101516. https://doi.org/10.1016/j.scs.2019. 101516

De Dominicis S, Fornara F, Cancellieri UG et al (2015) We are at risk, and so what? place attachment, environmental risk perceptions and preventive coping behaviours. J Environ Psychol 43:66-78

de Moel H, Aerts JCJH, Koomen E (2011) Development of flood exposure in the Netherlands during the 20th and 21st century. Glob Environ Chang 21:620-627. https://doi.org/10.1016/j.gloenvcha. 2010.12.005

De Silva MMGT, Kawasaki A (2018) Socioeconomic vulnerability to disaster risk: a case study of flood and drought impact in a rural Sri Lankan community. Ecol Econ 152:131-140

Domeneghetti A, Carisi F, Castellarin A, Brath A (2015) Evolution of flood risk over large areas: quantitative assessment for the Po river. J Hydrodyn 1527:809-823

Eckstein D, Hutfils M-L, Winges M (2019) Global climate risk index 2019: who suffers most from extreme weather events? weatherrelated loss events in 2017 and 1998 to 2017. Germanwatch, Bonn

Eckstein D, Künzel V, Schäfer L, Winges M (2020) Global climate risk index 2020: who suffers most from extreme weather events? weather-related loss events in 2018 and 1999 to 2018 . Germanwatch, Bonn

EM-DAT (2020) https://wwwemdatbe/. Accessed 6 October 2020

First Street Foundation (2020) First street foundation mission. https:// firststreet.org/mission/. (Accessed 3 Jan 2021)

Frigerio I, Ventura S, Strigaro D, Mattavelli M, de Amicis M, Mugnano S, Boffi M (2016) A GIS-based approach to identify the spatial variability of social vulnerability to seismic hazard in Italy. Appl Geogr 74:12-22

Garcia-Ayllon S (2018) Long-term GIS analysis of seaside impacts associated to infrastructures and urbanization and spatial correlation with coastal vulnerability in a Mediterranean area. Water 10(11):1642. https://doi.org/10.3390/w10111642

Gifford R (2011) The dragons of inaction: psychological barriers that limit climate change mitigation and adaptation. Am Psychol 66: 290-302

Gifford R, Scannell L, Kormos C, Smolova L, Biel A, Boncu S, Corral V, Güntherf H, Hanyu K, Hine D, Kaiser FG, Korpela K, Lima LM, Mertig AG, Mira RG, Moser G, Passafaro P, Pinheiro JQ, Saini S, Sako T, Sautkina E, Savina Y, Schmuck P, Schultz W, Sobeck K, 
Sundblad EL, Uzzell D (2009) Temporal pessimism and spatial optimism in environmental assessments: an 18-nation study. J Environ Psychol 29:1-12

Giuliani MV (2003) Theory of attachment and place attachment. In: Bonnes M, Lee T, Bonaiuto M (eds) Psychological theories for environmental issues. Ashgate, Aldershot, pp 137-170

Grothmann T, Reusswig F (2006) People at risk of flooding: why some residents take precautionary action while others do not. Nat Hazards 38(1-2):101-120

Gu H, Du S, Liao B et al (2018) A hierarchical pattern of urban social vulnerability in Shanghai, China and its implications for risk management. Sustain Cities Soc 41:170-179

Hidalgo MC, Hernández B (2001) Place attachment: conceptual and empirical questions. J Environ Psychol 21(3):273-281

Ho MC, Shaw D, Lin S, Chiu YC (2008) How do disaster characteristics influence risk perception? Risk Anal 28(3):635-643

Hudec O, Reggiani A, Šiserová M (2018) Resilience capacity and vulnerability: a joint analysis with reference to Slovak urban districts. Cities 73:24-35

IPCC (2014) Climate change 2014 mitigation of climate change summary for policymakers and technical summary

IPCC (2018) Summary for policymakers In: Global Warming of $15^{\circ} \mathrm{C}$ An IPCC Special Report on the impacts of global warming of $15^{\circ} \mathrm{C}$ above pre-industrial levels and related global greenhouse gas emission pathways, in the context of strengthening the global response to the threat of climate change, sustainable development, and efforts to eradicate poverty. World Meteorological Organization, Geneva

Jabareen Y (2015) The risk city: cities countering climate change: emerging planning theories and practices around the world. Springer, New York and London

Jansen SJT (2020) Place attachment, distress, risk perception and coping in a case of earthquakes in the Netherlands. J Housing Built Environ $35: 407-427$

Jansen E, Christensen JH, Dokken T, Nisancioglu PL, Bo MV, Capron E, Guo C, Jensen MF, Langen PL, Pedersen RA, Yang S, Bentsen M, Ajaer HA, Sadatzki H, Sessford E, Stendel M (2020) Past perspectives on the present era of abrupt Arctic climate change. Nat Clim Chang 10:714-721

Jha CK, Gupta V, Chattopadhyay U, Sreeraman BA (2017) Migration as adaptation strategy to cope with climate change: a study of farmers' migration in rural India. Int J Clim Chang Str. https://doi.org/10. 1108/IJCCSM-03-2017-0059

Jiang Y, Zevenbergena C, Ma Y (2017) Urban pluvial flooding and stormwater management: a contemporary review of China's challenges and "sponge cities" strategy. Environ Sci Pol 80:132-143

Kellogg WW, Schware R (2019) Climate change and society. Published in cooperation with the Aspen Institute for Humanistic Studies Program on Food. Climate and the World's Future, Boulder

Kelman I, Gaillard JC, Mercer J (2015) Climate change's role in disaster risk reduction's future: beyond vulnerability and resilience. Int J Disaster Risk Sci 6(1):21-27

Khailania DK, Pererab R (2013) Mainstreaming disaster resilience attributes in local development plans for the adaptation to climate change induced flooding: a study based on the local plan of Shah Alam City, Malaysia. Land Use Policy 30:615-627

Khajehei S, Ahmadalipour A, Shao W, Moradkhani H (2020) A placebased assessment of flash flood hazard and vulnerability in the contiguous United States. Sci Rep 10(1):1-12

Khan S (2012) Vulnerability assessments and their planning implications: a case study of the Hutt Valley, New Zealand. Nat Hazards 64: $1587-1607$

Koks EE, Jongman B, Husby TG, Botzen WJW (2015) Combining hazard, exposure and social vulnerability to provide lessons for flood risk management. Environ Sci Pol 47:42-52. https://doi.org/10. 1016/j.envsci.2014.10.013
Lavigne F, De Coster B, Juvin N et al (2008) People's behaviour in the face of volcanic hazards: perspectives from Javanese communities, Indonesia. J Volcanol Geotherm Res 172:273-287

Lee CH, Lin SH, Kao CL, Hong MY, Huang PC, Shih CL, Chuang CC (2020) Impact of climate change on disaster events in metropolitan cities-trend of disasters reported by Taiwan national medical response and preparedness system. Environ Res 183:109186. https:// doi.org/10.1016/j.envres.2020.109186

Lee YJ (2014) Social vulnerability indicators as a sustainable planning tool. Environ Impact Assess Rev 44:31-42

Lee YJ, Lin SY (2019) Vulnerability and ecological footprint: a comparison between urban Taipei and rural Yunlin, Taiwan. Environ Sci Pollut Res 27:1-14. https://doi.org/10.1007/s11356-019-05251-6

Lewicka M (2010) On the varieties of people's relationships with places: Hummon's typology revisited. Environ Behav 3:676-709

Lewicka M (2011) On the varieties of people's relationships with places: Hummon's typology revisited. Environ Behav 3:676-709

Malik K, Rahman SM, Khondaker AN, Abubakar IR, Aina YA, Hasan MA (2019) Renewable energy utilization to promote sustainability in GCC countries: policies, drivers and barriers. Environ Sci Pollut Control Ser 26(20):20798-20814

Marigi SN (2017) Climate change vulnerability and impacts analysis in Kenya. Am J Clim Chang 6:52-74

Mavromatidi A, Briche E, Claeys C (2018) Mapping and analyzing socio-environmental vulnerability to coastal hazards induced by climate change: an application to coastal Mediterranean cities in France. Cities 72:189-200

Meagher BR, Cheadle AD (2020) Distant from others, but close to home: the relationship between home attachment and mental health during COVID-19. J Environ Psychol 72 (2020) 101516

Michel-Guillou E, Krien N, Meur-Ferec C (2016) Inhabitants of coastal municipalities facing coastal risks: understanding the desire to stay. Papers on Social Representations 25(1):81-21

Mishra S, Mazumdar S, Suar D (2010) Place attachment and flood preparedness. J Environ Psychol 30:187-197

Motoyoshi T (2006) Public perception of flood risk and communitybased disaster preparedness In S Ikeda, T Fukuzono, T Sato (Eds) A better integrated management of disaster risks: toward resilient society to emerging disaster risks in mega-cities. National Research Institute for Earth Science and Disaster Prevention. pp121-134

Mysiak J, Testella F, Bonaiuto M, Carrus G, De Dominicis S, Ganucci Cancellieri U (2014) Flood risk management in Italy: challenges and opportunities for the implementation of the EU flood directive (2007/60/EC). Nat Hazards Earth Syst Sci 13:2883-2890

Nguyen TT, Ngo HH, Guo W, Wang XC, Ren N, Li G, Ding J, Liang H (2019) Implementation of a specific urban water management sponge city. Sci Total Environ 652:147-162

Nozawa M, Watanabe T, Katada N, Minami H, Yamamoto A (2008) A residents' awareness and behaviour regarding typhoon evacuation advice in Hyogo Prefecture, Japan. Int Nurs Rev 55:20-26

Okitasari M, Sunam R, Mishra R et al (2019) Governance and national implementation of the 2030 Agenda: lessons from voluntary national reviews. United Nations Univ Inst Adv Study Sustain Policy Br $18: 1-4$

O'Sullivan JJ, Bradford RA, Bonaiuto M, De Dominicis S, Rotko P, Aaltonen J, Waylen K, Langan SJ (2012) Enhancing flood resilience through improved risk communications. Nat Hazards Earth Syst Sci 12:2271-2282

Paton D, Burgelt PT, Prior T (2008) Living with bushfire risk: social and environmental influences on preparedness. Aust J Emerg Manag 23: $41-48$

Platt RH (1998) Planning and land use adjustments in historical perspective. Coop with Nat Confronting Nat hazards with land-use Plan Sustain communities 27-56

Proshansky HM, Fabian AK, Kaminoff R (1983) Place-identity: physical world socialization of the self. J Environ Psychol 3(1):57-83 
Qiang Y, Lam NSN, Cai H, Zou L (2017) Changes in exposure to flood hazards in the United States. Ann Am As Geogr 107:1332-1350. https://doi.org/10.1080/24694452.2017.1320214

Raymond CM, Brown G (2010) The measurement of place attachment: personal, community, and environmental connections. WEBER J Environ Psychology 30(4):422-434

Razem M (2020) Place attachment and sustainable communities. Architecture_MPS 17 1(2020):3. https://doi.org/10.14324/ 111444amps2020v17i1003

Roder G, Sofia G, Wu Z, Tarolli P (2017) Assessment of Social vulnerability to floods in the floodplain of Northern Italy. Weather Clim Soc 9:717-737. https://doi.org/10.1175/WCAS-D-16-0090.1

Ruiz C, Hernandez B (2014) Emotions and coping strategies during an episode of volcanic activity and their relations to place attachment. J Environ Psychol 38:279-287

Sajjad H, Jain P (2014) Assessment of socio-economic vulnerabilities among urban migrants in South-East Delhi, India. J Stud Soc Sci 7(1):65-81

Scannell L, Gifford R (2010) The relations between natural and civic place attachment and pro-environmental behavior. J Environ Psychol 30:289-297

Scannell L, Gifford R (2014) Comparing the theories of interpersonal relations and place attachment. In: Manzo LC, Devine-Wright $\mathrm{P}$ (eds) Place attachment: advances in theory, methods, and applications. Routledge, New York, pp 23-36

Scannell L, Gifford R (2017) Place attachment enhances psychological need satisfaction. Environ Behav 49(4):359-389

Schilar H, Keskitalo ECH (2018) Tourism activity as an expression of place attachment-place perceptions among tourism actors in the Jukkasjärvi area of northern Sweden. Scand J HospTour 18(S1): S42-S59

Schipper L, Pelling M (2006) Disaster risk, climate change and international development: scope for, and challenges to, integration. Disasters 30(1):19-38

Schultz PW, Milfont TL, Chance RC, Tronu G, Luís S, Ando K, Rasool F, Roose PL, Ogunbode CA, Castro J, Gouveia VV (2014) Crosscultural evidence for spatial bias in beliefs about the severity of environmental problems. Environ Behav 46:267-302

Song Z, Daryanto A, Soopramanien D (2019) Place attachment, trust and mobility: three-way interaction effect on urban residents' environmental citizenship behavior. J Bus Res 105:168-177

Spaans M, Waterhout B (2017) Building up resilience in cities worldwide - Rotterdam as participant in the resilient cities programme. Cities 61:109-116

Su Y, Sun XP, Zhao F (2017) Trust and its effects on the public's perception of flood risk: a social science investigation of the middle and lower reaches of the Yangtze River. J Flood Risk Manag 10(4):487498

Takao K, Motoyoshi T, Sato T, Fukuzondo T, Seo K, Ikeda S (2004) Factors determining residents' preparedness for floods in modern megalopolises: the case of the Tokai flood disaster in Japan. J Risk Res 7(7-8):775-787

Tarhan C, Aydin C, Tecim V (2016) How can be disaster resilience built with using sustainable development? Procedia Soc Behav Sci 216: 452-459

Tate E, Rahman MA, Emrich CT, Sampson CC (2021) Flood exposure and social vulnerability in the United States

Terpstra T, Gutteling JM, Geldof GD, Kappe LJ (2006) The perception flood risk and water nuisance. Water Sci Technol 54(6):431-439

Thorup-Binger C, Charania NA (2019) Vulnerability and capacities of international students in the face of disasters in Auckland, New Zealand: a qualitative descriptive study. Int J Disaster Risk Reduct. https://doi.org/10.1016/jijdrr2019101136

UN (2019) The Future is Now: Science for Achieving Sustainable Development

UN Habitat (2013) State of the world's cities 2012/2013: Prosperity of cities. Routledge, London

Uzzell DL (2000) The psycho-spatial dimension of global environmental problems. J Environ Psychol 20(4):307-318

van Valkengoed AM, Steg L (2019) Meta-analyses of factors motivating climate change adaptation behavior. Nat Clim Chang 9:158-163

van Veelen B, Haggett C (2017) Uncommon ground: the role of different place attachments in explaining community renewable energy projects. Sociol Rural 57(S1):533-554. https://doi.org/10.1111/soru. 12128

Wang C, Wu J, He X, Ye M, Liu W, Tang R (2019) Emerging trends and new developments in disaster research after the 2008 Wenchuan Earthquake. Int J Environ Res Public Health 16(1):29. https://doi. org/10.3390/ijerph16010029

Wing OEJ, Bates PD, Sampson CC, Smith AM, Johnson KA, Erickson TA (2017) Validation of a $30 \mathrm{~m}$ resolution flood hazard model of the conterminous United States. Water Resour Res 53:7968-7986. https://doi.org/10.1002/2017WR020917

Zhang H, Huang Z, Green BC, Qiu S (2017) Place attachment and attendees' experiences of homecoming event. J Sport Tour 22(3):227246

Publisher's note Springer Nature remains neutral with regard to jurisdictional claims in published maps and institutional affiliations. 